\title{
KẾT QUẢ BƯớC ĐẦU ỨNG DỤNG KỸ THUÂTT VÒI VOI CẢI TIẾN CỦA BỆNH VIỆN HỮU NGHI VIỆT ĐỨC
}

\section{TÓM TẮT}

Mục tiêu: Giới thiệu và đánh giá kết quả bước đầu ứng dụng kỹ thuâtt "vòi voi cải tiến" của bệnh viện Hữu Nghị Việt Đức điều trị bệnh động mạch chủ ngực phức tạp một thì. Đối tượng và phương pháp nghiên cứu: Nghiên cứu mô tả hồi cứu các bệnh nhân được phẫu thuật sử dụng phương pháp vòi voi cải tiến tại Trung tâm Tim mạch và Lồng ngực bệnh viện Hữu Nghị Việt Đức từ 01/01 đến $30 / 12$ năm 2020. Có 18 bệnh nhân tham gia nghiên cứu, nam giới

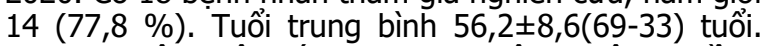
Theo nguyên nhân có $02(11,1 \%)$ bệnh nhân - phồng động mạch chủ ngực; 16 (88,9\%) bệnh nhân- lóc đổng mach chủ type $\mathrm{A}$, trong đó cấp tính có $55.6 \%$. Mổ lại có $02(11,1 \%)$ bệnh nhân, 3(16,7\%) bệnh nhân có hội chứng Marphan và $02(11,1 \%)$ bênh nhhân suy thận mạn độ III. Tất cả bệnh nhân được phẫu thuật theo một quy trình thống nhất. Bảo vệ não bằng tưới máu não chọn lọc hai bên, hạ nhiệt độ vừa $28^{\circ} \mathrm{C}$, theo dõi bão hòa oxi não bằng máy MAS̆IMO. Kết quả: Không có bệnh nhân tử vong sau mổ. Các kỹ thuật đã thực hiên: phẫu thuât vòi voi cải tiến đơn thuần - 16 $(88,9 \%)$; phẫu thuật vòi voi cải tiến và phẫu thuật Bentall - 02 $(11,1 \%)$. Thời gian tuần hoàn ngoài cơ thể - 186,2 49,7 phút (330-136); thời gian cặp động mạch chủ $-112,7 \pm 42,6$ phút (205-68); Thời gian ngừng tưần hoàn $-32,6 \pm 10,3$ phút $(48-20)$, thời gian phẫu thuật $6,1 \pm 0,9$ giờ $(8-5)$. Biến chứng: không có bệnh nhân chảy máu mổ lại, 4 (22,2\%) bênh nhân - mở khí quản, thở máy kéo dài,4 (22,2\%)suy thận cấp cần lọc máu. Leak type 1 có $2(11,1 \%)$ bệnh nhân. Kết luận: Phẫu thuật vòi voi cải tiến của Bểnh viện Hữu Nghị Việt Đức bước đâuu cho kết quả tốt, an toàn.

Tư khóa: Bệnh động mạch chủ ngực, Kỹ thuật vòi voi, Lóc động mạch chủ.

\section{SUMMARY}

INITIAL RESULTS OF USING VIET DUC UNIVERSITY HOSPITAL'S MODIFICATION OF FROZEN ELEPHANT TRUNT TECHNIQUE

Objective: To present surgical technique and initial results of using Viet Duc University Hospital Modification of Frozen Elephant Trunk (FET) to treat complex thoracic aortic diseases in one stage. Material and method: There were a retrospective, descriptive study of consecutive patients, who underwent FET operation at cardiovascular and

\section{${ }^{1}$ Bệnh viện Hữu Nghị Việt Đức}

${ }^{2}$ Đai hoc Y Hà Nôi

Chịu trách nhiệm chính: Phùng Duy Hồng Sơn

Email: hongsony81@yahoo.com

Ngày nhận bài: 22.2.2021

Ngày phản biên khoa họ: 31.3.2021

Ngày duyệt bài: 12.4.2021

\section{Phùng Duy Hồng Sơn ${ }^{1,2}$ và cộng sự}

thoracic center, Viet Duc University Hospital from 01 January to 30 December 2020. There are eighteen patients, including in this study. Fourteen $(77,8 \%)$ patients were man. The average age was $56,2 \pm 8,6(69-$ $33)$ years. There were two $(11,1 \%)$ patients, who had thoracic aortic aneurysm; Sixteen (88,9\%) - aortic dissection, in whom ten (55.6\%) were in acute A type. two $(11,1 \%)$ patients had undergone previous aortic operations, three $(16,7 \%)$ patients had Marphan's syndrome and two $(11,1 \%)$ had III -stage of chronic renal failure. All patients underwent FET procedure by unique protocol. Brain protection was achieved by antegrade bilateral selective cerebral perfusion and moderate hypothermia $\left(28^{\circ} \mathrm{C}\right)$ in all cases, Using MASIMO machine to control brain oxygenation. Result: There was no dead. Sixteen $(88,9 \%)$ patients was used isolated FET, two $(11,1 \%)-\mathrm{FET}+$ Bentall procedure. Bypass time was $186,2 \pm 49,7$ minutes (330-136); Cross clam time $-112,7 \pm 42,6$ minutes $(205-68)$; Time of

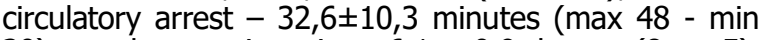
$20)$, total operating time $6,1 \pm 0,9$ hours $(8-5)$. Complication: There was no bleeding, 4 (22,2\%) patients had prolong ventilation and require tracheotomy, haemodialysis by acute renal failure in $4(22,2 \%)$ patients, Leak type 1 in $2(11,1 \%)$ patients. Conclusion: The use of FET Modification by Viet Duc University Hospital was effective, safe and gave good results.

Key words. Thoracic aortic disease, Frozen elephant trunk, Aortic dissection.

\section{I. ĐẶT VẤN ĐỀ}

Bệnh lý động mạch chủ (ĐMC) ngực phức tạp là bệnh lý ĐMC khi tổn thương lan tỏa ĐMC lên, quai ĐMC và $Đ M C$ xuống. Điều trị bệnh lý này luôn là thách thức cho các phẫu thuật viên tim mạch. Năm 1983 Bost và cộng sự đề xuất kỹ thuật vòi voi và đến nay trở phương pháp chính cho điều trị bệnh lý này ${ }^{1}$. Hạn chế của kỹ thuật vòi voi kinh điển là miệng nối xa nằm sâu, khó cầm máu, thời gian mổ kéo dài, tổn thương thần kinh trong mổ và cần mổ 2 cuộc mổ lớn, khác nhau. Với sự ra đời và phát triển của can thiệp nội mạch, sử dụng stent graft động mạch chủ đã khắc phục được các nhược điểm trên và có rất nhiều kỹ thuật vòi voi cải tiến đã được đề xuất ${ }^{2,3}$. Hiện trên thị trường có hai loại vật liệu chính để thực hiện FET là Thoraflex (Terumo) và Evita open plus (Jotec), tuy nhiên giá thành cao, khó có khả năng ứng dụng rộng rãi tại Việt Nam. Vì vậy tại bệnh viện Hữu Nghị Việt Đức chúng tôi đã cải tiến kỹ thuật này theo cách riêng, bước đầu cho kết quả tốt và tiết kiệm chi phí điều trị trong khi vẫn đảm bảo chất lượng. Trong nghiên 
cứu này chúng tôi miêu tả kỹ thuật cải tiến và đánh giá kết quả bước đầu ứng dụng kỹ thuật này trên lâm sàng.

Kỹ thuật cải tiến tại bệnh viện hữu nghị việt đức: Kỹ thuật vòi voi cải tiến được thực hiện cho bệnh nhân có tổn thương ĐMC lên, quai ĐMC và ĐMC xuống. Phẫu thuật bắt đầu như mổ tim hở thay ĐMC. Canuyn ĐM nách phải, mở đường giữa xương ức, 01 canuyn tĩnh mạch, phẫu tích đặt lắc các nhánh quai động mạch chủ. Bắt đầu tuần hoàn ngoài cơ thể, cắt khâu ĐM cảnh chung trái sát gốc, tưới máu não chọn lọc ĐM cảnh chung trái. Cắt khâu ĐM dưới đòn trái sát gốc, làm miệng nối mạch nhân tạo số 8 vào động mạch dưới đòn. Cặp động mạch chủ, bảo vệ tim. Hạ thân nhiệt $28^{\circ} \mathrm{C}$. Tưới máu não chọn lọc xuôi dòng hai bên. Theo dõi bão oxi não bằng máy MASIMO. Ngừng tuần hoàn, cắt ĐMC lên kiểu thay bán phần quai ĐMC. Đặt Stent graft động mạch chủ từ ngang động mạch cảnh chung trái xuống bằng đoạn phụ Medtronic Valiant Captivia (over size $5-10 \%$ ). Khâu vắt chỉ prolen $5-0$ ép Stent graft với thành quai $Đ M C$ vị trí chân thân động mạch cánh tay đâu (hình $1 A$ ). Làm miệng nối mạch nhân tạo Dacron đường kính 24-30mm với quai động mạch chủ (phía trong là Stent graft, phía ngoài tăng cường bằng đệm hình $1 \mathrm{~B}$ ). Phục hồi lại tuần hoàn cơ thể qua canuyn động mạch nách phải. Làm miệng nối mạch nhân tạo với ĐMC lên ngay trên xoang Valsalva kỹ thuật "sandwitch". Phục hồi tim đâp lại. Cắm động mạch nhân tạo số 8 đã nối với ĐM dưới đòn trái với ĐMC lên nhân tạo vị trí kim dẫn lưu gốc ĐMC kiểu tận bên, Nối Đ̇M cảnh trái vào mạch nhân tạo số 8 tận-bên (hình $1 \mathrm{C}$ ). Ngừng tuần hoàn ngoài cơ thể, kết thúc cuộc mổ như thường quy.

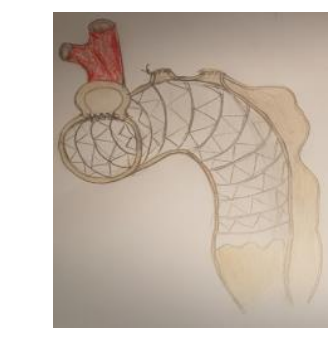

$\boldsymbol{A}-$

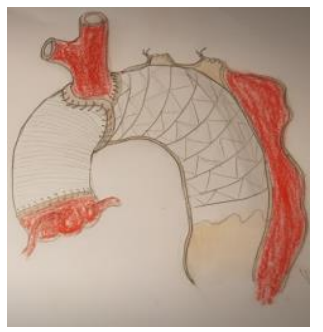

B-Thay ĐMC lên và bán phän quai ĐMC

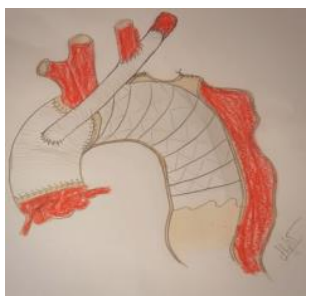

C - Nôi mạch nhân tạo với ĐM cảnh chung trái và ĐM dưới đòn trái

Hình 1: Các bước phẫu thuật vòi voi cải tiến tại bệnh viện Hữu Nghị Việt Đức.

II. ĐỐI TƯỢNG VÀ PHƯƠNG PHÁP NGHIÊN CỨU

Nghiên cứu mô tả hồi cứu các bênh nhân được phẫu thuật sử dụng phương pháp vòi voi cải tiến tại Trung tâm Tim mạch và Lồng ngực bệnh viện Hữu Nghị Việt Đức từ $01 / 01$ đến 30/12 năm 2020. Có 18 bệnh thỏa mãn yêu câu. Số liệu được thu thập từ hể thống bệnh án điện tử của bệnh viện, các bệnh nhân được chụp cắt lớp ví tính kiểm tra trước khi ra viện và sau $1,3,6$ tháng.

Tất cả bênh nhân được phẫu thuật theo một quy trình thống nhất. Bảo vệ não bằng tưới máu chọn lọc hai bên $(\mathbf{1 0 - 1 5} \mathbf{~ m L} / \mathbf{k g} / \mathbf{m i n})$, hạ nhiệt độ vừa $-28^{\circ} \mathrm{C}$, theo dõi bão hòa oxi não bằng máy MASIMO.

\section{Xử lý số liệu}

+ Các số liệu được xử lý bằng các thuật toán $Y$ học trên chương trình SPSS 2.0.

+ Các thông số được tính toán qua tỷ lệ phần trăm, trị trung bình, độ lệch chuẩn.

+ Kết quả, biểu đồ, đồ thị được tính toán và vẽ tự động trên máy vi tính.

\section{Đạo đức nghiên cứu}

- Nghiên cứu được tiến hành sau khi thông qua hội đồng đạo đức bệnh viện HN Việt Đức.

- Bệnh nhân và gia đình đồng ý tham gia nghiên cứu.

- Nghiên cứu nhằm mục đích nâng cao chất lượng khám chữa bệnh và đào tạo bác sỹ chuyên nghành.

\section{KẾT QUẢ NGHIÊN CứU}

Có 18 bệnh nhân thỏa mãn nghiên cứu, các đặc điểm lẩm sàng và cận lâm sàng được trình bày bảng 1 :

Bảng 1: Đặc điểm lâm sàng của bệnh nhân nghiên cứu

\begin{tabular}{|c|c|c|c|}
\hline \multicolumn{2}{|c|}{ Đặc điếm } & FET $(\mathbf{n = 1 8})$ & $\mathbf{\%}$ \\
\hline \multicolumn{2}{|c|}{ Tuổi trung bình (năm) } & $\begin{array}{c}56,2 \pm 8,6 \\
(69-33)\end{array}$ & \\
\hline \multirow{2}{*}{$\begin{array}{c}\text { Giới } \\
\text { tính }\end{array}$} & Nam & 14 & 77,8 \\
\cline { 2 - 4 } & Nữ & 4 & 22,2 \\
\hline \multicolumn{2}{|c|}{ Cao huyết áp } & 16 & 88,9 \\
\hline \multicolumn{2}{|c|}{ Dái tháo đường } & 5 & 31,3 \\
\hline \multicolumn{2}{|c|}{ Suy thận mạn độ III } & 2 & 11,1 \\
\hline \multicolumn{2}{|c|}{ Marphan } & 3 & 16,7 \\
\hline \multicolumn{2}{|c|}{ Mố lại sau mố ĐMC ngực } & 2 & 11,1 \\
\hline
\end{tabular}




\begin{tabular}{|c|c|c|c|}
\hline \multicolumn{2}{|c|}{$\begin{array}{l}\text { Liệt dây thần kinh quặt } \\
\text { ngược trái }\end{array}$} & 1 & 5,6 \\
\hline \multicolumn{2}{|c|}{ Thiếu máu cấp tính chân } & 2 & 11,1 \\
\hline \multirow{4}{*}{$\begin{array}{l}\text { Bênh } \\
\text { chính }\end{array}$} & Lóc ĐMC type A & 16 & 88,9 \\
\hline & $\begin{array}{l}\text { Lóc ĐMC type A } \\
\text { cấp tính }\end{array}$ & 10 & 55,6 \\
\hline & $\begin{array}{c}\text { Lóc ĐMC type A } \\
\text { mạn tính }\end{array}$ & 6 & 33,3 \\
\hline & Phồng ĐMC ngực & 2 & 11,1 \\
\hline & tở van ĐMC & 8 & 50 \\
\hline
\end{tabular}

Tuối trung bình của bệnh nhân là 56,2 tuổi, nam giới chiếm đa số $77,8 \%$, cao huyết áp gặp ở 88,9\% trường hợp, hội chứng Marphan gặp ở 16,7\% trường hợp. Trước mổ có 11,1\% bệnh nhân suy thận mạn và có phẫu thuật thay ĐMC lên do lóc Đ̇MC type $A$. Chiếm đa số là bệnh nhân lóc ĐMC type $A 88,9 \%$ và ở giai đoạn cấp tính có $55,6 \%$, trong đó $11,1 \%$ có biến chứng thiếu máu cấp tính chi.

Các chỉ số trong mổ được trình bày ở bảng 2 . Mổ cấp cứu chiếm 55,6\%, thiết lập tuần hoàn ngoài cơ thể đa phần qua đặt canuyn ĐM nách $(61,1 \%)$, có $2(11,1 \%)$ trường hợp đặt cả ĐM nách và ĐM đùi bên thiếu máu. Tất cả bệnh nhân dùng một canuyn tĩnh mạch vào nhĩ phải, hạ nhiệt độ $28^{\circ} \mathrm{C}$, tưới máu não chọn lọc hai bên cho tất cả các trường hợp. Mạch nhân tạo dung chủ yếu là mạch cõ $26,28,30$ với tỉ lể gần tương đương, các cõ stent graft hay dung là 30,32 với độ dài đa phần là $200 \mathrm{~mm}(77,8 \%)$, đa phần bệnh nhân được thay động mạch chủ lên $(98,9 \%)$, thời gian mổ trung bình 6 giờ. Có 2(11,1\%) bệnh nhân thay gốc ĐMC kỹ thuật Bentall.

\section{Bảng 2: Các chỉ số trong mô.}

\begin{tabular}{|c|c|c|c|}
\hline \multicolumn{2}{|c|}{ Chỉ số nghiên cứu } & $\begin{array}{c}\text { Số bệnh } \\
\text { nhẩn } \\
(\mathrm{n}=\mathbf{1 8})\end{array}$ & $\begin{array}{l}\text { Tỉ lệ } \\
\text { (\%) }\end{array}$ \\
\hline \multicolumn{2}{|r|}{ Mố cấp cứu } & 10 & 55,6 \\
\hline \multirow{4}{*}{$\begin{array}{l}\text { Vị trí } \\
\text { canuyn } \\
\text { ĐMC }\end{array}$} & Thân cánh tay đầu & 3 & 16,7 \\
\hline & ĐM nách & 11 & 61,1 \\
\hline & ĐM đùi & 2 & 11,1 \\
\hline & $\begin{array}{l}\text { Cả 2: ĐM đùi và } \\
\text { ĐM nách }\end{array}$ & 2 & 11,1 \\
\hline \multicolumn{2}{|c|}{ Thời gian mổ (phút) } & $\begin{array}{c}365,4 \pm 56,4 \\
{[300-420]}\end{array}$ & \\
\hline \multicolumn{2}{|c|}{$\begin{array}{l}\text { Thời gian tuần hoàn } \\
\text { ngoài cơ thể (phút) }\end{array}$} & $\begin{array}{c}186,2 \pm 49,7 \\
{[142-330]}\end{array}$ & \\
\hline \multicolumn{2}{|c|}{ Thời gian cặp chủ (phút) } & $112,7 \pm 42,6$ & \\
\hline \multicolumn{2}{|c|}{ Nhiêt độ cơ thế, ${ }^{\circ} \mathrm{C}$} & 28 & \\
\hline \multicolumn{2}{|c|}{$\begin{array}{l}\text { Thời gian ngưưng tuần } \\
\text { hoàn, min }\end{array}$} & $\begin{array}{c}32,6 \pm 10,3 \\
{[18-58]}\end{array}$ & \\
\hline \multicolumn{4}{|c|}{ Đường kính mạch nhân tạo (mm) } \\
\hline & 24 & 2 & 11,1 \\
\hline & 26 & 6 & 33,3 \\
\hline & 28 & 5 & 27,8 \\
\hline
\end{tabular}

\begin{tabular}{|c|c|c|}
\cline { 2 - 3 } 30 & 5 & 27,8 \\
\hline Kích thước stent graft (mm) \\
\hline 26 & 1 & 5,5 \\
\hline 28 & 1 & 5,5 \\
\hline 30 & 9 & 50 \\
\hline 32 & 7 & 38,9 \\
\hline Chîêu dài stent graft (mm) \\
\hline 150 & 4 & 22,2 \\
\hline 200 & 14 & 77,8 \\
\hline \multicolumn{3}{|c|}{ Phâu thuâat ở ĐMC lên và gốc ĐMC } \\
\hline Phâu thuật Bentall & 2 & 11,1 \\
\hline Thay ĐMC lên & 16 & 98,9 \\
\hline
\end{tabular}

Các biến chứng sau mố được trình bày ở bảng 3. Không có bệnh nhân từ vong sớm tại viện. Các bệnh nhân nghiên cứu cũng không gặp các tai biến, biến chứng như tai biến mạch máu não, tổn thương tủy sống, liệt thần kinh quặt ngược, chảy máu cần mổ lại, thiếu máu tạng cần can thiệp. Có 01 bệnh nhân chảy máu sau mổ cần truyền máu nhưng không cần mổ lại. Các biến chứng như loc máu do suy thân cấp, mở khí quản thở máy kéo dài gặp ở $11,1 \%$ bệnh nhân. $5,5 \%$ bệnh nhân được can thiệp mach thì 2 .

Bảng 3: Các chỉ số sau mổ và tai biến biến chứng.

\begin{tabular}{|c|c|c|}
\hline Chỉ số nghiên cứu & $\begin{array}{c}\text { Số bệnh } \\
\text { nhẩn } \\
(n=18)\end{array}$ & $\begin{array}{l}\text { Tỉ lệ } \\
(\%)\end{array}$ \\
\hline Tỉ lệ tử vong 30 ngày & 0 & 0 \\
\hline Tai biến mạch máu nẫo & 0 & 0 \\
\hline Tốn thương tủy sống & 0 & 0 \\
\hline $\begin{array}{c}\text { Liệt thần kinh quằt ngược } \\
\text { sau mổ }\end{array}$ & 0 & 0 \\
\hline Chảy máu mố lại & 0 & 0 \\
\hline $\begin{array}{c}\text { Chuyên hông cầu khối } \\
>5 \text { đơn vị }\end{array}$ & 0 & 0 \\
\hline Thiếu máu tang cần cân thiêp & 0 & 0 \\
\hline Lọc máu tạm thời & 4 & 22,2 \\
\hline Mơ khí quản & 4 & 22,2 \\
\hline Thời gian thở máy (ngày) & \begin{tabular}{|c|}
$11,2 \pm 10$ \\
$(1-31)$
\end{tabular} & \\
\hline Thời gian nằm hồi sức & $\begin{array}{c}19,2 \pm 11,7 \\
(7-45)\end{array}$ & \\
\hline Thời gian nằm viện & $\begin{array}{c}32,3 \pm 11,8 \\
(17-55)\end{array}$ & \\
\hline Can thiêp tiếp thì 2 & 1 & 5,5 \\
\hline
\end{tabular}

Sau mố $100 \%$ được theo dõi định kỳ, khám lại sau 1,3 và 6 tháng. Không có bệnh nhân tử vong trong quá trình theo dõi. Kết quả chụp cắt lớp vi tính (CT) trong quá trình theo dõi trình bày ở bảng 4.

Bảng 4: Kêt quả chup CT sau mô.

\begin{tabular}{|c|c|c|}
\hline Các chỉ số nghiên cứu & $\mathbf{N = 1 8}$ & Tỉ lệ(\%) \\
\hline CT sau mố & 16 & 88.9 \\
\hline Sau 1 tháng & 18 & 100 \\
\hline
\end{tabular}




\begin{tabular}{|c|c|c|}
\hline Sau 3 tháng & 13 & 72,2 \\
\hline Endoleak loại I & 2 & 11,1 \\
\hline Huyết khối lòng giả*, $\mathrm{n}(\%)$ & & \\
\hline $1 / 3$ trên ĐMC xuống & 16 & 88,9 \\
\hline $1 / 3$ giữa ĐMC xuống & 10 & 55,6 \\
\hline $1 / 3$ dưới ĐMC xuống & 8 & 44,4 \\
\hline
\end{tabular}

\section{BÀN LUÂ̂N}

Nghiên cứu này nhằm đánh giá kết quả ứng dụng phương pháp vòi voi cải tiến tại trung tâm chúng tối trong năm 2020. Tử vong tại viện và trong theo dõi của chúng tôi là không có trường hợp nào, trong khi đó tỉ lệ tử vong sớm tại viện trên thế giới dao động từ $9-16 \%{ }^{4}$. Điều này có thể được giải thích là do chúng tôi chọn những bệnh nhân không quá nặng cho kỹ thuật vòi voi cải tiến, và số bệnh nhân nghiên cứu còn ít. Đối với những trường hợp nặng, cao tuổi (>70 tuổi) chúng tôi chọn phương pháp đơn giản, thời gian mổ ngắn như thay ĐMC lên đơn thuần hoặc thay bán phần quai ĐMC sau đó theo dõi, khi có chỉ định làm FET thì 2. Có 2 bệnh nhân trong nghiên cứu được làm FET thì 2, cả 2 bệnh nhân đều diễn biến thuật lợi.

Tai biến thần kinh, đặc biệt là thần kinh trung ương sau phẫu thuật là biến chứng lớn bao gồm thiếu mãu não và tủy sống, là chỉ số quan trọng đánh giá độ an toàn của kỹ thuật. Các báo cáo trên thế giới tỉ lệ tổn thương não và liệt tủy sống này giao động lần lượt là $8.8-15.2 \%$ và $5.6-$ $8.8 \%$ cao hơn ở bệnh nhân lóc ĐMC type $\mathrm{A}$ cấp tính ${ }^{4-6,6,7}$. Trong nghiên cứu của chúng tôi không gặp bệnh nhân biến chứng lớn về thần kinh như: chết não, nhồi máu não, liệt tủy, nhưng có gặp tình trạng kích thích sau mổ và trở lại bình thường bằng điều trị nội khoa. Có thể do như đã nói ở trên do bệnh nhân được chọn không quá nặng và tuổi không cao. Liêt tủy sống do thiếu máu tủy là một biến chứng kinh điển của $\mathrm{FET}^{2,5}$, một số tác giả cho rằng nếu đặt stent graft quá đổt sống ngực T8 có thể tang nguy cơ liệt tủy ${ }^{5-7}$, một nghiên cứu đa trung tâm ARCH lại không tìm được mối liên quan này ${ }^{8}$. Chiều dài stent graft của nhóm bệnh nhân nghiên cứu chủ yếu là $200 \mathrm{~mm}(77,8 \%)$, còn lại là $150 \mathrm{~mm}$. Tuy nhiên do đặt ở ngang thân cánh tay đâu nên xa hơn so với các tác giả khác đặt ở sau ĐM dưới đòn trái. Liệt thần kinh quă̆t ngược là biến chứng được nhắc đên với tî lệ khá cao 13,2-19,8\% 4,6, liệt thần kinh hoành $4,4 \%{ }^{6}$, chúng tôi cũng không gặp liệt thần kinh hoành, liệt thần kinh quặt ngược sau mổ do kỹ thuật của chúng tôi không làm miệng nối ở ngang ĐṂ dưới đòn trái.

Cầm máu sau mổ là nhiệm vụ khó khăn cho các kỹ thuật can thiệp ở quai ĐMC, đặc biệt là trong giai đoạn lóc cấp tính. Tuy nhiên trong kỹ thuật của chúng tôi miệng nối mạch nhân với động mạch chủ ở mức quai ĐMC giữa $\mathrm{TABC}$ và ĐM cảnh chung trái, kiểu thay bán phần quai ĐMC. Vị trí này không quá sâu nên dễ thực hiện, dễ cầm máu, ít nguy cơ tổn thương thần kinh hơn. Chúng tôi không gặp khó khăn trong vấn đề cầm máu và không có trường hợp phải mổ lại do chảy máu, không có trường hợp cần chuyền nhiều máu ( $>5$ đơn vị). Trong khi đó tỉ lệ chảy máu ở các phương pháp vòi voi khác dao động với tỉ lệ khá cao $18,9-25 \%$ 4,6.

Suy thận cấp cần lọc máu sau mổ chiếm 22,2\% đêu ở bệnh nhân lóc ĐMC cấp tính, có 2 bệnh nhân suy thận mạn giai đoạn IV, mố có kễ hoạch, cả 2 bệnh nhân đều không cần lọc máu sau mổ. Kết quả này tương tự các công bố các nghiên cứu tham khảo của Liakupoulos và Kremer ${ }^{4,6}$. Có 4 bệnh nhân cần thở máy kéo dài và phải mở khí quản, nhìn chung thời gian thở máy, thời gian nằm hồi sức và thời gian nằm viện tương ứng với độ nặng của bệnh và tương đương các nghiên cứu trên thế giới $4,6,7$.

Chụp cắt lớp vi tính sau mổ có 2 bệnh nhân có leak type 1a từ chân thân động mạch cánh tay đầu, sau đó chúng tôi rút kinh nghiệm khâu ép thành $Đ M C$ vào stent graft vị trí chẩn $T A B C$ có đệm, và không gặp trường hợp nào thêm. Một số tác giả gặp tình trạng tương tự và cũng có nhũng cải tiến riêng để hạn chế biến chứng này. Tỷ lệ huyết khối long giả đoạn stent Graft là $88,9 \%$ so với các công bố khoảng $93-99 \%{ }^{4}$ và tỉ lệ huyết khối lòng gải giảm dần khi đi xuống các đoạn dưới. Có 1 bệnh nhân cần can thiệp bước hai do túi phình phía dưới, các bệnh nhân endoleak do điều kiện kinh tế nên chưa can thiệp tiếp thì hai và tiểp tục theo dõi.

Hạn chế nghiên cứu là nghiên cứu đơn trung tâm, số lượng bệnh nhân nghiên cứu ít và thời gian theo dõi còn ngắn. Trong tương lai tác giả sẽ có những số liệu lớn hơn và thời gian theo dõi dài hơn, chính xác hơn.

\section{KẾT LUÂ̂N}

Phương pháp cải tiến kỹ thuật vòi voi tại bv HN Việt Đức dễ thục hiện, tiết kiệm chi phí và cho kết quả bước đầu tốt và an toàn.

\section{TÀI LIẸU THAM KHẢO}

1. Borst HG, Walterbusch G, Schaps D. Extensive Aortic Replacement using "Elephant Trunk" Prosthesis. Thorac Cardiovasc Surg. 1983;31(1):37-40. doi:10.1055/s-2007-1020290

2. Di Marco L, Pantaleo A, Leone A, Murana G, Di Bartolomeo R, Pacini D. The Frozen Elephant 
Trunk Technique: European Association for CardioThoracic Surgery Position and Bologna Experience. Korean J Thorac Cardiovasc Surg. 2017;50(1):1-7. doi: $10.5090 /$ kjtcs.2017.50.1.1

3. Roselli EE, Idrees JJ, Bakaeen FG, et al. Evolution of Simplified Frozen Elephant Trunk Repair for Acute DeBakey Type I Dissection: Midterm Outcomes. Ann Thorac Surg. 2018;105(3):749-755.

doi:10.1016/j.athoracsur.2017.08.037

4. Liakopoulos OJ, Kroener A, Sabashnikov A, et al. Single-center experience with the frozen elephant trunk procedure in 111 patients with complex aortic disease. J Thorac Dis. 2020;12(10):5387-5397. doi:10.21037/jtd-20-1531

5. Damberg A, Schälte $G$, Autschbach $R_{\text {, }}$ Hoffman A. Safety and pitfalls in frozen elephant trunk implantation. Ann Cardiothorac Surg.
2013;2(5):669-676.

doi:10.3978/j.issn.2225319X.2013.09.16

6. Kremer J, Preisner F, Dib B, et al. Aortic arch replacement with frozen elephant trunk technique - a single-center study. J Cardiothorac Surg. 2019;14(1):147. doi:10.1186/s13019-019-0969-9

7. Hohri Y, Yamasaki T, Matsuzaki Y, Hiramatsu T. Early and mid-term outcome of frozen elephant trunk using spinal cord protective perfusion strategy for acute type A aortic dissection. Gen Thorac Cardiovasc Surg. 2020;68(10):1119-1127. doi: $10.1007 / \mathrm{s} 11748-020-01328-z$

8. Frozen elephant trunk does not increase incidence of paraplegia in patients with acute type A aortic dissection - The Journal of Thoracic and Cardiovascular Surgery. Accessed April 13, 2021. https:// www.jtcvs.org/ article/S0022-5223(19)30800-1/fulltext.

\section{NGHIÊN CỨU KỸ THUÂT GÂY KHAC ĐỜM TRONG CHẨN ĐOÁN LAO PHỔI AFB ÂM TÍNH VÀ MộT Số ĐĂC ĐIỂM LÂM SÀNG, CẬN LÂM SÀNG CỦA BỆNH NHÂN ĐƯợC CHẨN ĐOÁN XÁC ĐỊNH}

\section{TÓM TẮT}

Đăt vấn đề: Gây khạc đờm đã được chứng minh là phương pháp lấy bệnh phẩm an toàn, dễ thực hiện, giá trị cao, ít xâm lấn, có thể thực hiện lại nhiều lần, giá thành rẻ. Do đó, có thể sử dụng gầy khạc đờm để chẩn đoán lao phổi AFB âm tính - vốn có biểu hiên lâm sàng nghèo nàn, chẩn đoán xác định còn khó khăn, phức tap và thường phải dựa vào kỹ thuât hiên đại tốn kém. Vì vậy chúng tôi thực hiện nghiển cứu này nhằm 2 mục tiêu: 1) Mô tả một số đăc điểm của kỹ thuât gây khac đờm trong chẩn đoán lao phổi AFB âm tính, 2) Phân tích một số đặc điểm lâm sàng, cận lâm sàng của bệnh nhân lao phổi AFB âm tính. Đối tượng và phương pháp nghiên cứu: Thiết kế nghiên cứu mô tả cắt ngang trên những bệnh nhân nghi lao, có ít nhất 2 mâuu đờm thường quy $A F B$ âm tính. Kết quả: có 309 bênh nhân tham gia vào nghiên cứu, trong đó tỷ lệ gẩy khạc đờm thành công là $98,1 \%$. Tỷ lệ có biến chứng là $13,6 \%$ găp biến chứng; biến chứng hay gặp nhất là khó thở nhẹ $(88,1 \%)$. Trong 298 bênh nhân đủ tiêu chuẩn phân tích có 45 bênh nhân được chẩn đoán xác định lao phổi bằng tiêu chuẩn cấy MGIT dương tính với vi khuẩn lao. Kappa giữa 2 phương pháp GKĐ và NSPQ là 0,81 , $\mathrm{p}=0,0000$, hai phương pháp có độ đồng thuận rất tốt. Các triệu chứng lâm sàng như mệt mỏi, gầy sút cân, ra mồ hôi trộm và hình ảnh trên X-quang điển hình

*Bênh Viện Hữu Nghi

**Trướng Đai Hoc Y Hà Nôi

Chịu trách nhiệm chính: Nguyễn Minh Sang

Email: sangmedi@gmail.com

Ngày nhận bài: 24.2.2021

Ngày phản biên khoa hoc: 30.3.2021

Ngày duyệt bài: 9.4.2021

\section{Nguyễn Minh Sang*, Phan Thu Phương**}

như thâm nhiễm, xơ vôi có ý nghĩa trong chẩn đoán lao phổi $(p<0,05)$. Kết luân: Kỹ thuật gây khạc đờm khá an toàn, tỷ lệ lấy được bệnh phẩm rất cao, và có đồng thuận rất tốt với nội soi phế quản trong chẩn đoán lao phổi AFB âm tính. Một số triệu chứng lâm sàng và cận lâm sàng có giá trị trong chẩn đoán lao phối AFB ẩm tính là: mệt mỏi, gây sút cân, ra mồ hô trộm, $X$ quang có hình ảnh thâm nhiếm, hình ảnh xơ vôi.

Từ khóa: Gây khạc đờm, lao phổi AFB âm tính

\section{SUMMARY \\ INDUCED SPUTUM IN DIAGNOSIS OF SMEAR-NEGATIVE PULMONARY TUBERCULOSIS, CLINICAL AND SUBCLINICAL CHARACTERISTICS OF DIAGNOSED PATIENTS}

Background: Induced sputum has been shown to be a safe, easy-to-implement, high-value, low-invasive method that can be repeated and cheaply. Therefore, it can be used to diagnose smear-negative pulmonary tuberculosis, which often had poor clinical symptoms, and difficult in definitive diagnosis, complicated and often requires expensive modern technology. We conducted this study with 2 purposes: 1) Describe some features of the induced sputum technique in smear-negative diagnosis, 2) Analyze some clinical and subclinical characteristics of patients with smearnegative pulmonary tuberculosis. Methods: A crosssectional study design was used in patients suspected pulmonary tuberculosis, who had at least 2 spontaneous sputum smear - negative. Results: 309 patients participated in the study, of which induced sputum successful rate was $98.1 \%$. The rate of complications was $13.6 \%$, the most common one was mild dyspnea (88.1\%). Of the 298 patients eligible for analysis, 45 were diagnosed with pulmonary 